\title{
Seroprevalence of Coxiella burnetii in Dairy Cattle and Camel in Sudan
}

\author{
Mohammed Osman Hussien, ${ }^{1,}$ Khalid Abdallah Enan, ${ }^{1}$ Shima Hassan Alfaki, ${ }^{2}$ Rana Alhibir Gafar, ${ }^{1}$ \\ Khalid Mohamed Taha, ${ }^{3}$ and Abdel Rahim Mohamed El Hussein ${ }^{2}$ \\ ${ }^{1}$ Department of Microbiology, Central Laboratory, Ministry of Higher Education and Scientific Research, Khartoum, Sudan \\ ${ }^{2}$ Central Veterinary Research Laboratory (CVRL), Animal Resources Research Corporation (ARRC), El Amarat, Khartoum, Sudan \\ ${ }^{3}$ Atbara Veterinary Research Laboratory, Animal Resources Research Corporation (ARRC) \\ "Corresponding author: Mohammed Osman Hussien, Department of Microbiology, Central laboratory, Ministry of Higher Education and Scientific Research, P.O. Box: 7099, \\ Khartoum, Sudan. E-mail: moh200432@hotmail.com \\ Received 2016 October 18; Revised 2016 November 08; Accepted 2016 November 08.
}

\begin{abstract}
Background: Coxiella burnetii (C. burnetii) is the causative agent of Q fever, a zoonotic disease that is prevalent worldwide. Domestic and companion animals are the main reservoirs of infection. Humans mainly acquire the infection through inhalation of contaminated aerosols.

Objectives: This study was carried out to detect the prevalence of $C$. burnetii antibodies in dairy cattle sera samples collected in nine states and in camel sera samples in four states in Sudan during May 2015 - March 2016.

Methods: A total of 244 cattle sera and 76 camel sera samples were collected and screened for anti- $C$. burnetii IgG antibodies, using a commercial Q fever antibody ELISA test kit (IDEXX).

Results: In dairy cattle, the results indicated an overall $29.92 \%$ prevalence of $C$. burnetii antibodies whereas an overall $64.5 \%$ prevalence rate was detected in dairy camel.

Conclusions: Our data indicate that C. burnetii is widespread in dairy cattle and camel in Sudan. Both animal and human health workers in Sudan should be aware of the possibility of Q fever infection in animals and humans.
\end{abstract}

Keywords: Coxiella Burnetii, Q Fever, Cattle, Camel, Sudan

\section{Background}

Q fever is a widespread zoonotic infection caused by C. burnetii, an obligate intracellular gram-negative organism (1). Domestic ruminants are considered the main source of human infections. C. burnetii does not usually cause clinical symptoms in animals, but can sometimes cause late stage abortions, death after birth and delivery of weak offspring. After animal infection, frequent shedding of highly resistant organisms occurs in birth products, vaginal discharges, feces and milk $(2,3)$. C. burnetii infections are not uncommon in humans, and outbreaks of $\mathrm{Q}$ fever that sometimes affect thousands of people are welldocumented (4). Recently, Q fever proved to be a more common cause of severe febrile illness than malaria among hospitalized patients in northern Tanzania (5).

In Sudan, Q fever has been recognized since 1952 when C. burnetii was first isolated from ticks collected at the Cairo Municipal Abattoir on infested camels and bulls imported from Sudan (6). Taylor et al. (7) also indicated that 28 out of $401(6.9 \%)$ human sera collected in different regions of Sudan were positive for C. burnetii antibodies.

\section{Objectives}

To generate updated and reliable data, it is important to allow proper risk assessment of $C$. burnetii infection. Owing to the meager and old data on Q fever disease available since 1988 in dairy cattle and camels in Sudan, this survey was conducted to determine the prevalence of anti- C. burnetii antibodies in cattle and camels in nine States in Sudan during May 2015 - March 2016.

\section{Methods}

\subsection{Study Design}

This cross-sectional survey included nine states of Sudan. Sample size estimation was calculated, using the formula $\mathrm{n}=4 \mathrm{PQ} / \mathrm{L} 2$, where $\mathrm{n}$ is the required number of animals to be examined; $P$ is a known or estimated prevalence; and $\mathrm{Q}=(1-\mathrm{P})$; $\mathrm{L}$ is the allowable error. The number of animals estimated, using this formula assuming $10 \%$ prevalence rate, was 144 . Since location-to-location variation was expected, the sample size was increased and all collected sera $(n=244)$ were tested. 


\subsection{Sample Collection}

Collection of animal samples was reviewed and was in accordance with the animal welfare code of Sudan. Five $\mathrm{mL}$ of blood samples were collected from 244 adult, apparently healthy dairy cattle and from 76 healthy camels in nine States in Sudan (Blue Nile, El Gezira, Kassala, Khartoum, North Darfur, North Kordofan, River Nile, Sennar and White Nile States) during May 2015-March 2016 (Figure 1). These locations were selected based on their importance for livestock raising. In each area, samples were collected from at least four groups of dairy cattle and camels that were kept apart. Selection of groups was made randomly and the formal mechanism used was lottery. Sera were obtained by centrifugation at $1500 \mathrm{rpm} / \mathrm{min}$. for 10 minutes and kept at $-20^{\circ} \mathrm{C}$ until tested.

\subsection{Serological Assay}

Commercial Q fever antibody indirect ELISA test kits (IDEXX Laboratories, USA) were used to detect anti- C. burnetii IgG antibodies based on the manufacturer's instructions. The sample optical densities (OD) were measured by a microplate ELISA reader (Asys Expert Plus, Austria) at $450 \mathrm{~nm}$. The sample to positive control ratio (S/P ratio) was then determined, using the following formula:

$100 \times \frac{O D \quad \text { Sample }-O D \quad \text { Negative }}{O D \quad \text { Positive }-O D \quad \text { negative }}$

The cutoff value of antibody titer is $\geq 40 \%$; i.e., all samples that have $S / P$ ratio $\geq 40$ are considered positive as indicated in the kit literature.

\section{Results}

C. burnetii antibodies were detected in dairy cattle and camels in all areas tested with varying prevalences. The seroprevalence rates in dairy cattle ranged from 3.3\% in Nile River to $100 \%$ in White Nile State. The prevalence rates were highest in White Nile (100\%) and Blue Nile (90.5\%), moderate in El Gezira (53.3\%) and North Kordofan (50\%), and was lowest in Sennar (13.3\%), Khartoum (9.4\%), Kassala and North Darfur (6.7\%) and River Nile (3.3\%) States, with an overall prevalence of $29.92 \%$.

The prevalence rates of antibodies in camels ranged from $20 \%$ in Kassala to $87.5 \%$ in North Kordofan State. The prevalence rates were highest in North Kordofan (87.5\%) and River Nile (86.7\%), moderate in El Gezira (40\%) and lowest in Kassala (20\%) States, with an overall prevalence of $64.5 \%$.

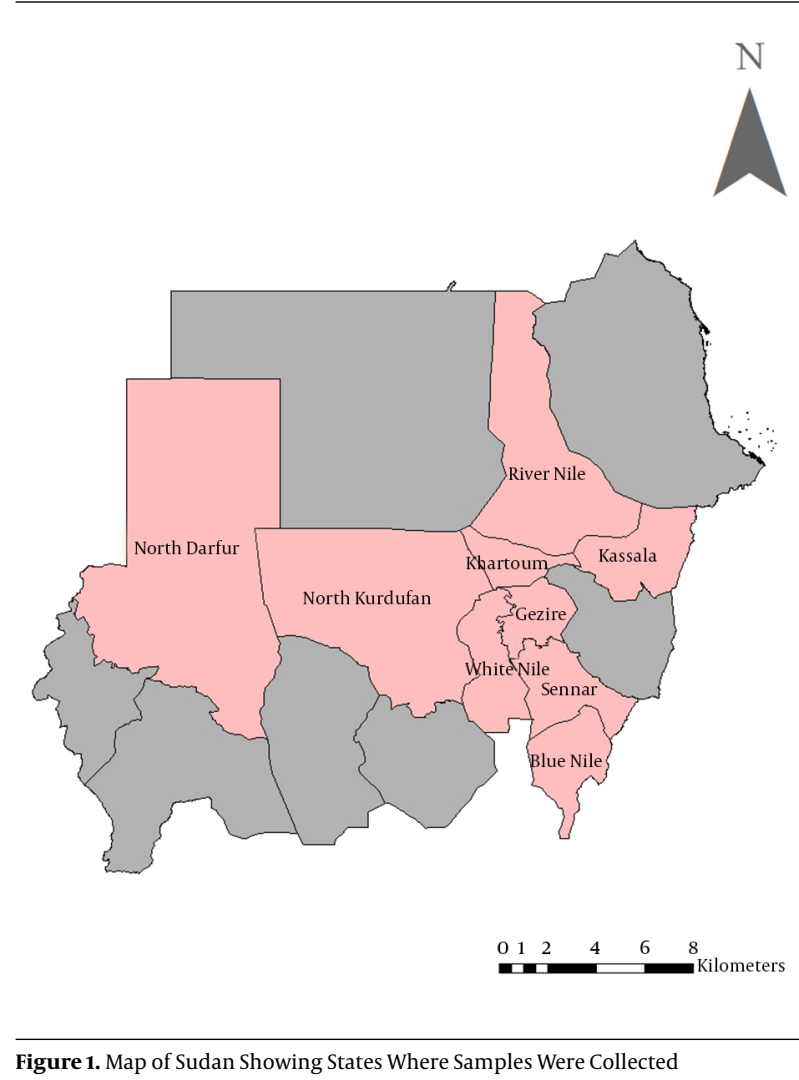

\section{Discussion}

In this study, ELISA was used to detect antibodies to $C$. burnetii as the technique is very suitable for epidemiologic studies. Moreover, it is more sensitive, faster and convenient than both complement fixation test (CFT) and indirect immunofluorescent antibody (IFA) (8). Our results indicate that dairy cattle and camels are commonly exposed to C. burnetii in Sudan, with an overall seropositivity of 29.92\% and $64.5 \%$ in cattle and camels, respectively.

Hamza (9) recorded a seroprevalence of $1.6 \%$ in Sudanese cattle, using capillary agglutination test (CAT). Harbi and Awad El Karim (10) reported that the prevalence rate of anti- $C$. burnetii antibodies in Sudanese camel's sera was $11.9 \%$ and $12.2 \%$ in El Butana and Kassala regions, respectively, using capillary agglutination test. The difference in the prevalence between these studies and ours might be partially attributed to the different techniques used in determining these prevalences. Notwithstanding, there is more than four decades difference between timing of the works, and during this time C. burnetii infection might have intensively increased due to many factors such as an increase in animal population and intensification of animal breeding. 
The differences in prevalence rates between the States herein reported may be attributed to local ecological factors, type of management and practices, flock size... etc. that might influence the transmission rates and infection with C. burnetii.

In this study, the overall seropositivity of $\mathrm{Q}$ fever detected in dairy cattle and camels (29.92\% and 64.5\%) was higher than that reported in goats $(24.22 \%)$ in Sudan by Hussien et al. (11). This may, among other factors, be due to the fact that cattle and camels are more susceptible to tick infestation than goats. Ticks and aerosol infection are the main routes of $C$. burnetii transmission to domestic animals (12).

$\mathrm{Q}$ fever has been reported in many countries with different prevalence rates since the disease was described in 1935 (13). The seroprevalence of Q fever reported in this study in cattle (29.92\%) was higher than that reported for cattle in Egypt (13\%), Senegal (4\%), Ghana (18\%), Chad (7\%) and South Africa (8\%) (14-18), and it was lower than that reported in Nigeria (55\%) and Cameroon (32\%) (19-21). In this study, the prevalence of Q fever in camels (64.5\%) was lower than that reported in Chad (80\%) (22) and higher than that reported for camel in Saudi Arabia (15.9\%) using PCR (23). These differences in seroprevalence rates among different areas may reflect the intensity of infections due to several reasons as mentioned earlier.

Transmission of C. burnetii through milk and semen is also possible $(2,24)$. All animal hosts for $Q$ fever secrete C. burnetii in milk; thus, consumption of raw or unpasteurized milk or milk products could be a source of infection to humans (2). Consumption of raw camel milk is a widespread habit in the Sudanese society. However, generally, consumption of raw milk and milk products from all domestic species should be avoided to reduce the risk of infection with $\mathrm{Q}$ fever as well as with other milk and milk products borne pathogens.

Fever is one of the main symptoms of $\mathrm{Q}$ fever infections in humans. This can lead to incorrect diagnosis based on clinical symptoms alone since other febrile diseases, such as malaria, brucellosis, typhoid, visceral leishmaniasis, arboviral diseases, fevers of unknown origin (F.U.O) etc. are prevalent in Sudan. Hence, public health workers should consider Q fever diagnosis especially in those in close contact with animals.

In conclusion, $\mathrm{Q}$ fever is prevalent in dairy cattle and camels in Sudan. Therefore, more countrywide epidemiological studies on Q fever in both farm animals and humans should be undertaken.

\section{References}

1. Cutler SJ, Bouzid M, Cutler RR. Q fever. J Infect. 2007;54(4):313-8. doi: 10.1016/j.jinf.2006.10.048. [PubMed: 17147957].
2. Maurin M, Raoult D. Q fever. Clin Microbiol Rev. 1999;12(4):518-53. [PubMed: 10515901].

3. Porter SR, Czaplicki G, Mainil J, Guatteo R, Saegerman C. Q Fever: current state of knowledge and perspectives of research of a neglected zoonosis. Int J Microbiol. 2011;2011:248418. doi: 10.1155/2011/248418. [PubMed: 22194752].

4. Schimmer B, Dijkstra F, Vellema P, Schneeberger PM, Hackert V, ter Schegget R, et al. Sustained intensive transmission of Q fever in the south of the Netherlands, 2009. Euro Surveill. 2009;14(19) [PubMed: 19442401].

5. Crump JA, Morrissey AB, Nicholson WL, Massung RF, Stoddard RA, Galloway RL, et al. Etiology of severe non-malaria febrile illness in Northern Tanzania: a prospective cohort study. PLoS Negl Trop Dis. 2013;7(7):e2324. doi: 10.1371/journal.pntd.0002324. [PubMed: 23875053].

6. Taylor RM, Mount EA, Hoogstraal H, Dressler HE. The presence of coxiella burnetii (q fever) in Egypt. J Egypt Public Health Assoc. 1952;27(4):123-8.

7. Taylor RM, Kingston JR, Rizk F. Serological (complement-fixation) surveys for $\mathrm{Q}$ fever in Egypt and the Sudan, with special reference to its epidemiology in areas of high endemicity. Arch Inst Pasteur Tunis. 1959;36:529-56.

8. El-Mahallawy HS, Kelly P, Zhang J, Yang Y, Zhang H, Wei L, et al. High seroprevalence of Coxiella burnetii in dairy cattle in China.Trop Anim Health Prod. 2016;48(2):423-6. doi: 10.1007/s11250-015-0968-3. [PubMed: 26669596].

9. Hamza ME. A serological survey for the detection of $Q$ fever antibodies in the sera of animals in the Sudan. Bull Epizoot Dis Afr. 1962;10:55-7.

10. Harbi MS, el-Karim MH. Serological investigation into $Q$ fever in Sudanese camels (Camelus dromedarius). Bull Epizoot Dis Afr. 1972;20(1):15-7. [PubMed: 5078478].

11. Hussien M, ElFahal A, Enan K, Taha K, Mohammed M, Salih D, et al. Seroprevalence of $\mathrm{q}$ fever in goats in the Sudan. Veterinary World. 2012;5(7):394. doi:10.5455/vetworld.2012.394-397.

12. Kazar J. Q. . Rickettsiae and rickettsial diseases. In: Kazar J, Toman R, editors. Slovak academy of sciences. Bratislava; 1996.

13. Derrick EH. " Q" fever, a new fever entity: Clinical features, diagnosis and laboratory investigation. Medical Journal of Australia. 1937;2:28199.

14. Nahed HG, Khaled AAM. Seroprevalence of Coxiella burnetii antibodies among farm animals and human contacts in Egypt. J Am Sci. 2012;8:619-21.

15. Kamga-Waladjo AR, Gbati OB, Kone P, Lapo RA, Chatagnon G, Bakou $\mathrm{SN}$, et al. Seroprevalence of Neospora caninum antibodies and its consequences for reproductive parameters in dairy cows from DakarSenegal, West Africa. Trop Anim Health Prod. 2010;42(5):953-9. doi: 10.1007/s11250-009-9513-6. [PubMed: 19997972].

16. Adu-Addai B, Koney EB, Addo P, Kaneene J, Mackenzie C, Agnew DW. Importance of infectious bovine reproductive diseases: an example from Ghana. Vet Rec. 2012;171(2):47. doi: 10.1136/vr.100789. [PubMed: 22706039].

17. Domenech J, Trap D, Gaumont R. [Study of reproductive pathology in cattle in Central Africa: survey of chlamydiosis and Q fever]. Rev Elev Med Vet Pays Trop. 1985;38(2):138-43. [PubMed: 3842175].

18. Gummow B, Poerstamper N, Herr S. The incidence of Coxiella burnetii antibodies in cattle in the Transvaal. Onderstepoort J Vet Res. 1987;54(4):569-71. [PubMed: 3444611].

19. Adesiyun AA, Jagun AG, Tekdek LB. Coxiella burnetii antibodies in some Nigerian dairy cows and their suckling calves. Int J Zoonoses. 1984;11(2):155-60. [PubMed: 6534901].

20. Adesiyun AA, Jagun AG, Kwaga JK, Tekdek LB. Shedding of Coxiella burnetii in milk by Nigerian dairy and dual purposes cows. Int JZoonoses. 1985;12(1):1-5. [PubMed: 4055266].

21. Scolamacchia F, Handel IG, Fevre EM, Morgan KL, Tanya VN, Bronsvoort BM. Serological patterns of brucellosis, leptospirosis and 
Q fever in Bos indicus cattle in Cameroon. PLoS One. 2010;5(1):ee8623. doi: 10.1371/journal.pone.0008623. [PubMed: 20098670].

22. Schelling E, Diguimbaye C, Daoud S, Nicolet J, Boerlin P, Tanner M, et al. Brucellosis and Q-fever seroprevalences of nomadic pastoralists and their livestock in Chad. Prev Vet Med. 2003;61(4):279-93. [PubMed: 14623412].

23. Osama BM, Abdulrahman AJ, Riyadh SA, Mohammed AA, Amel
OB, Sawsan AO, Abdulaziz NA, Mansour FH. Coxiella burnetii, the causative agent of $\mathrm{Q}$ fever in Saudi Arabia: molecular detection from camel and other domestic livestock. Asian Pacific J Trop Med. 2014:7159.

24. Kruszewska D, Tylewska-Wierzbanowska S. Isolation of Coxiella burnetii from bull semen. Res Vet Sci. 1997;62(3):299-300. [PubMed: 9300554]. 